\title{
Alexandre Dumas, Les Frères corses
}

\section{Rita Severi}

\section{(2) OpenEdition}

\section{Journals}

\section{Edizione digitale}

URL: http://journals.openedition.org/studifrancesi/8297

DOI: 10.4000/studifrancesi.8297

ISSN: 2421-5856

\section{Editore}

Rosenberg \& Sellier

\section{Edizione cartacea}

Data di pubblicazione: 1 mai 2009

Paginazione: 191

ISSN: 0039-2944

\section{Notizia bibliografica digitale}

Rita Severi, «Alexandre Dumas, Les Frères corses», Studi Francesi [Online], 157 (LIII | I) | 2009, online dal 30 novembre 2015, consultato il 13 janvier 2021. URL: http://journals.openedition.org/studifrancesi/ 8297 ; DOI: https://doi.org/10.4000/studifrancesi.8297

Questo documento è stato generato automaticamente il 13 janvier 2021.

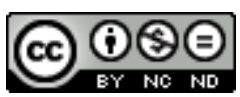

Studi Francesi è distribuita con Licenza Creative Commons Attribuzione - Non commerciale - Non opere derivate 4.0 Internazionale. 


\section{Alexandre Dumas, Les Frères corses}

\section{Rita Severi}

\section{NOTIZIA}

ALEXANDRE DUMAS, Les Frères corses, édition présentée, établie et annotée par Claude schopp, Paris, Gallimard, 2007, pp. 234.

Come sottolinea il curatore nella prefazione questo romanzo, pieno di dialoghi, di Dumas è prezioso per cogliere la transizione che in questo periodo si attua tra il drammaturgo e il romanziere. Ma la composizione de Les Frères corses, come molta prosa romanzata di Dumas risente anche del suo tirocinio come narratore di viaggi, come è ben evidente fin dall'incipit del romanzo dove si narra di una visita all'isola avvenuta nel 1841. Nel giugno 1840, quando Dumas in una lettera annuncia il proposito di visitare la Corsica, si trovava a Firenze con la compagna, l'attrice Ida Ferrer. In effetti il viaggio in Corsica non si concretizzò e il romanzo che egli pubblicò nel 1844 attinse alle impressioni che l'isola selvaggia gli aveva lasciato durante un breve viaggio nel 1835, al racconto Colomba di Prosper Mérimée (al quale dedicò poi il suo romanzo) che Dumas lesse presso il Gabinetto Vieusseux a Firenze, sulla «Revue des Deux Mondes» nel novembre 1840, e alla lettura del resoconto di A.C. Valery, Voyages en Corse, à l'île d'Elbe et en Sardaigne pubblicato nel 1837. La rustica, vendicativa Corsica, terra natale di Napoleone, per Dumas, diviene nel romanzo narrato in prima persona, l'emblema dello spazio incontaminato dove le antiche consuetudini, la tradizione, il buon costume e i valori antichi sono conservati con fierezza e si contrappongono alla civile, ma in realtà "barbara" metropoli di Parigi. I due fratelli gemelli Lucien e Louis de Franchi (che riprendono i nomi dei fratelli di Napoleone) scelgono di vivere due vite separate: il primo nella natia Corsica, il secondo a Parigi dove coltiva i suoi interessi culturali (ben esemplificati dall'elenco delle sue letture, p. 44), ma essi, pur vivendo così lontani, sono legati da vincoli ancestrali e comunicano telepaticamente. Quando Louis muore in duello, dopo aver ricevuto - come Amleto - la visione nel sonno del padre morto come 
segno premonitore, Lucien non solo avverte il dolore della morte del fratello, ma ne risente nel corpo che si ricopre di ecchimosi.

2 Il romanzo ebbe una grande fortuna dovuta agli adattamenti teatrali e, ai nostri tempi, alle molteplici versioni cinematografiche. Ricordo che persino Oscar Wilde dedicò una poesia, Fabien dei Franchi (osCAR WILDE, Complete Poetry, ed. by I. MURRAY, Oxford, World's Classics, 1997, p. 127) alla messa in scena de The Corsican Brothers di D. Boucicault del 1880-1881, nella quale Henry Irving recitava entrambi le parti dei due fratelli.

3 Quest'ottima edizione, curata da Claude Schopp, con un dossier finale di oltre 60 pagine, ci offre alcune ore di esclusiva e godibile evasione al modico prezzo di un caffé con croissant. 